\title{
PENADÉS MARTÍNEZ, I. (2015): PARA UN DICCIONARIO DE LOCUCIONES. DE LA LINGÜÍSTICA TEÓRICA A LA FRASEOLOGÍA PRÁCTICA. ALCALÁ DE HENARES: SERVICIO DE PUBLICACIONES DE LA UNIVERSIDAD DE ALCALÁ. 360 páginas
}

\author{
Alicia Merino GonZÁlez \\ Universidad de Alicante
}

Para un diccionario de locuciones. De la lingüística teórica a la fraseología práctica es un libro que aborda la problemática que suscita la elaboración de una obra lexicográfica, y en concreto, de la confección de un diccionario fraseológico. Así pues, desde el punto de vista fraseográfico se aporta aquella información relevante para llevar a cabo una obra lexicográfica de la envergadura del Diccionario de locuciones del español actual (DILEA).

La autora de esta obra, Inmaculada Penadés, realiza un recorrido detallado por las cuestiones que el autor de una obra lexicográfica debe tener en cuenta. Para ello, presenta los diferentes aspectos que pueden suscitar algún tipo de controversia y, a través de ejemplos de otros diccionarios fraseológicos y del DILEA, expone las opciones más adecuadas para facilitar la consulta al usuario.

En la introducción se muestra el punto de partida de esta obra: la denuncia de la confección de diccionarios fraseológicos por autores inadecuados, así como la despreocupación de las editoriales por la falta de rigurosidad de los mismos. A partir de esta realidad, la autora decide elaborar un libro en el que se expliciten los conocimientos tanto fraseológicos como lexicográficos que debe poseer quien decida embarcarse en una empresa de tal dimensión, así como los diferentes escollos que se encontrará en el camino. Asimismo, en los siguientes capítulos se glosan los estadios que conforman la confección de una obra fraseográfica, así como las partes de esta y los aspectos más relevantes. Para ello, la autora trae a colación diferentes diccionarios para mostrar las múltiples opciones, y, por otro lado, corroborar la falta de homogeneidad entre estos.

En el primer capítulo se presentan las disciplinas lingüísticas que convergen en la confección de una obra lexicográfica especializada en las unidades fraseológicas. Son tres las disciplinas implicadas y a lo largo de este capítulo se presenta el estudio individualizado y exhaustivo de cada una de ellas. La primera es la fraseología, disciplina que se encarga del estudio de las unidades fraseológicas con finalidades teóricas o aplicadas. La segunda

Para citar esta reseña / To cite this book review: Merino González, Alicia (2016). Reseña de Inmaculada Penadés Martínez (2015): Para un diccionario de locuciones. De la lingüística teórica a la fraseología práctica. Alcalá de Henares: Servicio de Publicaciones de la Universidad de Alcalá. ELUA, 30: 291-294. doi:10.14198/ELUA2016.30.16

Enlace / Link: http://dx.doi.org/10.14198/ELUA2016.30.16 
disciplina es la lexicografía, ámbito en el que según la autora se observa un abundante intrusismo, pues en ocasiones los autores no poseen los conocimientos necesarios para llevar a cabo dicha labor. Por último, en cuanto a la tercera disciplina, esta conjuga las mencionadas con anterioridad; se trata de la fraseografía, disciplina en torno a la cual se articulan los siguientes capítulos.

Las nociones clave que se deben tener en cuenta antes de la elaboración de un diccionario aparecen en el segundo capítulo, en el cual la autora muestra los pasos previos a la redacción de la obra lexicográfica de locuciones. De este modo, a través de su propia experiencia en la confección del DILEA, presenta y ejemplifica los primeros procedimientos como la elaboración del plan o proyecto del diccionario (conocido como planta), así como la adopción de los fundamentos teóricos sobre los que se sustenta la obra. Además, Inmaculada Penadés hace hincapié en la figura del destinatario, ya que se debería confeccionar la obra lexicográfica a partir de las necesidades del usuario al que se dirige. Por otro lado, en cuanto a las características de la persona que se disponga a elaborar una obra de esta índole, la autora destaca de nuevo la necesidad de poseer la base teórica adecuada tanto en el ámbito fraseológico como lexicográfico. Entre los procesos más relevantes, se encuentran la extracción de locuciones mediante fuentes lingüísticas/primerias y metalingüísticas/secundarias, y la selección de las locuciones que formarán parte del diccionario. En relación con la segunda cuestión, surge la siguiente pregunta: ¿qué unidades seleccionar y cómo delimitarlas? Esta problemática no es novedosa, ya que la delimitación de las unidades fraseológicas no está libre de controversia $\mathrm{y}$, por lo tanto, el debate en torno a esta sigue encima de la mesa. Al respecto, Inmaculada Penadés propone reducir las unidades fraseológicas a aquellas que desempeñen una función en la oración, por lo que se excluyen las paremias y las fórmulas rutinarias oracionales. Para finalizar con este capítulo, se aboga por la necesidad de recopilar las unidades fraseológicas en función del destinatario al que va dirigida la obra, y a los preceptos teóricos adoptados.

El tercer capítulo presenta el grueso de la obra, la redacción del diccionario de locuciones. En términos generales se pueden distinguir tres partes en una obra lexicográfica: introducción, cuerpo del diccionario y anexos. En relación con la introducción, es conveniente que en ella aparezcan los datos relacionados con las unidades que el usuario encontrará en esa obra, así como las marcas, la delimitación y la clasificación de estas unidades. En el caso del DILEA, la autora especifica qué se entiende por locución y cómo se lleva a cabo la clasificación, de este modo, se presentan las bases teóricas a partir de las cuales se articula la obra lexicográfica. Tras destacar la información que debería aparecer en la introducción, se lleva a cabo un recorrido por la macroestructura y microestructura, así como la contemplación de algunas cuestiones que hasta ahora no se han planteado. En cuanto a la macroestructura, comprende la estructura del diccionario y sus entradas y, en concreto, son dos los aspectos que adquieren protagonismo en este apartado: la ordenación y la lematización de las locuciones. El orden que siguen las diferentes entradas suele ser alfabético, pero esta labor presenta mayor complejidad al tratarse de unidades compuestas por dos o más lexemas. Así pues, la autora distingue dos tipos de ordenación alfabética, la discontinua (palabra por palabra) y la continua (por letras), y, a su vez, en cada entrada se establece un orden respetando las características de la ordenación seleccionada. No obstante, también cabe la posibilidad de llevar a cabo un orden no alfabético tras la palabra clave, tal y como se ilustra a través de ejemplos extraídos del Diccionario fraseológico del español moderno (Varela y Kubarth, 1994). De este modo, en este diccionario tras la palabra clave aparecen 
los fraseologismos según la categoría a la que pertenezcan (locuciones o expresiones), modo de proceder que puede confundir al usuario. La segunda cuestión relevante en relación con la macroestructura es la lematización y cuál de los elementos que conforman la locución se erige como palabra clave. Para despejar este interrogante es posible la adopción de tres criterios: estructural, semántico y categorial. De este modo, la autora define y analiza los tres criterios a través de ejemplos extraídos de obras lexicográficas especializadas en las unidades fraseológicas.

Una vez se han presentado aquellas cuestiones relacionadas con la macroestructura, se muestra la microestructura del diccionario, así como el tipo de información que debería abarcar y las contribuciones que la autora realiza al tener en cuenta cuestiones que hasta el momento no aparecían en el artículo lexicográfico. En primer lugar, Inmaculada Penadés presenta las definiciones de conceptos como lema y entrada para disipar las posibles dudas al respecto, asimismo, se muestra el cuerpo de artículo como la sección en la que se halla la información de interés para el usuario. Entre las decisiones a las que tendrá que hacer frente el lexicógrafo, se halla la inclusión o no de las valencias cuando se trata de una locución verbal. En segundo lugar, el polimorfismo suscita cierta controversia que la autora disuade mediante la adopción de los planteamientos de Porto Dapena (2002). De este modo, se redacta solo el artículo lexicográfico de la primera variante que aparece en la obra lexicográfica, mientras que en el resto de entradas se indicará dónde hallar dicha información. Por otro lado, respecto a la clasificación de las locuciones, se debe señalar la categoría y subcategoría, así como otras marcas que hagan referencia a la marcación diafásica o a la frecuencia. De hecho, las informaciones relacionadas con las últimas marcaciones se presentan como punto de divergencia entre diferentes obras lexicográficas, pues no hay unanimidad. Definir una unidad con las características de una locución no es tarea fácil y algunas de las dificultades que se deben superar están vinculadas con la estructura actancial y cómo elaborar una definición que se adecue a las necesidades del usuario y a la información que requiere. En el caso concreto del DILEA, se presentan los actantes y argumentos antes de la definición, mientras que las obras predecesoras a esta suelen mostrar esta información en el lema. Un aspecto que se mencionó con anterioridad es la redacción de las definiciones y cómo abordar esta cuestión, así pues, para presentar los tipos de definición, su estructuración y las características de estas, la autora adopta los fundamentos aportados por Porto Dapena (2002). De este modo, la contribución del autor mencionado se presenta como la premisa a partir de la cual se articulan tanto los aspectos teóricos como los prácticos, al realizar una disección pormenorizada de los tipos de definición y la delimitación de las acepciones de las locuciones. Al respecto, se debe traer a colación el papel crucial que desempeñan los ejemplos, ya que a través de estos se muestra el uso de la locución y nos permiten distinguir los diferentes actantes, así como delimitar una acepción del resto en función de los diferentes casos del fraseologismo. Por ello, la autora aboga por definir y delimitar una locución a partir de los ejemplos que se documenten de esta, pues, al fin y al cabo, es el uso de la lengua el que debe marcar la descripción de la misma. De este modo, sobre la postura adoptada por la autora en relación con los últimos aspectos tratados, se destaca la necesidad de mostrar el número de actantes y la naturaleza semántica, informaciones que aparecen en el DILEA como innovadoras. La controversia en torno a la definición de locuciones no es novedosa, pues en las obras lexicográficas se han adoptado diferentes tipos de definición, asimismo, al respecto la autora hace hincapié en tomar como punto de partida las necesidades del usuario 
para, a partir de estas, decantarse por la opción que se adecue a dichas necesidades.

Para finalizar con la microestructura, se propone la inclusión de otras informaciones que la autora ya tuvo en cuenta en la confección de sus otras lexicográficas dirigidas a estudiantes de español como lengua extranjera (DICLOCVER, DICLOCADV y DICLOCNAP). Resulta conveniente la redacción de este apartado debido a que la mayoría de las obras lexicográficas proporcionan la información básica en el artículo lexicográfico y en ocasiones se precisan aclaraciones, breves notas sobre la ortografía, la puntualización de determinados aspectos gramaticales, así como la alusión a la naturaleza pragmática de estas unidades. Además, se muestra la idoneidad de la complementación del artículo a través de la fraseología diacrónica, ya que esta aporta datos relacionados con la motivación de los fraseologismos, así como su evolución. No obstante, la autora es consciente de la dificultad que conlleva el estudio diacrónico de cada una de las locuciones que conforman nuestra lengua, por lo que no es posible incluir esta información en todas las entradas de la obra lexicográfica. Por último, el capítulo 3 se completa con un apartado dedicado a otras partes del diccionario en el que se manifiesta la posibilidad de redactar una sección de sinónimos y antónimos. Asimismo, se presentan diccionarios con un planteamiento diferente a los mencionados y analizados en los capítulos y apartados anteriores. Se trata de diccionarios temáticos y bilingües en los que se plantea el debate en torno a qué tipo de unidad debe ser el equivalente en español, si un fraseologismo u otro lexema simple o compuesto.

El cuarto capítulo está formado por las conclusiones que se extraen de la elaboración de una obra de las características del DILEA. De este modo, se presentan los aspectos a tener en cuenta para confeccionar con éxito y rigurosidad una obra lexicográfica de carácter fraseológico. Por último, la obra finaliza con el listado bibliográfico y el índice de locuciones empleadas a lo largo de sus páginas.

El valor de la obra que Inmaculada Penadés nos presenta estriba en la concepción del usuario como punto de partida para la elaboración de una obra lexicográfica, así como el abordaje de la problemática que suscita la confección de obras de esta índole. De este modo, a través de diccionarios fraseológicos se muestra el planteamiento de estos, así como las alternativas que existen para cubrir las necesidades del usuario. Por otra parte, cabe destacar la importancia que se le debe otorgar a la fundamentación teórica para la confección de un diccionario fraseológico riguroso, pues hay obras que presentan carencias en esta materia. Con anterioridad se han elaborado diccionarios fraseológicos que dejan entrever la necesidad de aportar otras informaciones en el artículo lexicográfico, así como la falta de homogeneidad en aspectos clave como la clasificación de las unidades y la ordenación. Por ello, Para un diccionario de locuciones. De la lingüística teórica a la fraseología práctica es una obra que permite indagar en la problemática que presentan los diferentes estadios de una obra lexicográfica especializada, así como la aportación de información novedosa que facilitará la consulta al usuario. 